\title{
Heavy metals, welding fumes, and other occupational exposures, and the risk of kidney cancer: A population-based nested case-control study in three Nordic countries
}

\author{
Irmina Maria Michalek $^{\mathrm{a}, *}$, Jan Ivar Martinsen ${ }^{\mathrm{b}}$, Elisabete Weiderpass ${ }^{\mathrm{b}, \mathrm{c}, \mathrm{d}, \mathrm{e}}$, Johnni Hansen ${ }^{\mathrm{f}}$, \\ Pär Sparen ${ }^{\mathrm{e}}$, Laufey Tryggvadottir ${ }^{\mathrm{g}, \mathrm{h}}$, Eero Pukkala ${ }^{\mathrm{a}, \mathrm{i}}$ \\ ${ }^{\text {a }}$ Faculty of Social Sciences, University of Tampere, Finland \\ ${ }^{\mathrm{b}}$ Department of Research, Cancer Registry of Norway, Institute of Population-Based Cancer Research, Oslo, Norway \\ ${ }^{c}$ Department of Community Medicine, Faculty of Health Sciences, University of Tromsø, The Arctic University of Norway, Tromsø, Norway \\ ${ }^{\mathrm{d}}$ Genetic Epidemiology Group, Folkhälsan Research Center and Faculty of Medicine, University of Helsinki, Helsinki, Finland \\ ${ }^{\mathrm{e}}$ Department of Medical Epidemiology and Biostatistics, Karolinska Institutet, Stockholm, Sweden \\ ${ }^{\mathrm{f}}$ Danish Cancer Society Research Center, Copenhagen, Denmark \\ ${ }^{\mathrm{g}}$ Icelandic Cancer Registry, Reykjavik, Iceland \\ ${ }^{\mathrm{h}}$ Faculty of Medicine, University of Iceland, Reykjavik, Iceland \\ ${ }^{\mathrm{i}}$ Finnish Cancer Registry, Institute for Statistical and Epidemiological Cancer Research, Helsinki, Finland
}

\section{A R T I C L E I N F O}

\section{Keywords:}

Kidney neoplasms

Occupational exposure

Heavy metals

Risk factors

Renal pelvis neoplasms

\begin{abstract}
A B S T R A C T
Objectives: To determine whether occupational exposure to heavy metals (chromium (VI), iron, nickel, lead) and welding fumes is associated with the risk of kidney cancer and to describe whether other occupational exposures included in the Job Exposure Matrix of the Nordic Occupational Cancer (NOCCA) study are associated with the risk.

Materials and methods: Nested case-control study among individuals registered in population censuses in Finland, Iceland, and Sweden in 1960-1990. A total of 59,778 kidney cancer cases, and 298,890 controls matched on sex, age, and country. Cumulative occupational exposures to metals (chromium (VI), iron, nickel, lead), welding fumes, and 24 other occupational exposure covariates, lagged 0, 10, and 20 years.

Results: Overall, there was no or very little association between kidney cancer and exposures studied. The risk was elevated in individuals with high exposure to asbestos (OR 1.19, 95\%CI 1.08-1.31). The risk was significantly decreased for individuals characterized with high perceived physical workload (OR 0.86, 95\%CI 0.82-0.91), high exposure to ultraviolet radiation (OR 0.85, 95\%CI 0.79-0.92), and high exposure to wood dust (OR 0.82 , 95\%CI $0.71-0.94$ ). The risk of kidney cancer under the age of 59 was elevated in individuals with high exposure to nickel (OR 1.49, 95\%CI 1.03-2.17). The risk of kidney cancer in age 59-74 years was elevated for individuals with high exposure to iron (OR 1.41, 95\%CI 1.07-1.85), and high exposure to welding fumes (OR 1.43, 95\%CI 1.09-1.89).

Conclusions: The only markedly elevated risks of kidney cancer were seen for the highest exposures of nickel and iron/welding fumes in specific age strata.
\end{abstract}

\section{Introduction}

Studies over the past three decades have provided valuable information on kidney cancer risk factors. Existing research recognizes the critical role played by tobacco smoking and obesity (Moch et al., 2016). Moreover, the important role of trichloroethylene and gamma radiation as carcinogenic agents that increase the risk of kidney cancer has been recognized by the International Agency for Research on
Cancer (IARC) (IARC, 2006). Other agents that IARC identified as potential carcinogens connected with kidney cancer are perfluorooctanoic acid, printing process, arsenic, and cadmium (IARC, 2006).

Effects of exposure to toxic heavy metals, apart from arsenic, have not been comprehensively examined. There is little published data on chromium and nickel (Boffetta et al., 2011; Ilychova and Zaridze, 2012; Langard, 1994; Rashidi and Alavipanah, 2016; Southard et al., 2012). Moreover, Pesch et al. (2000) demonstrated that occupational

\footnotetext{
* Corresponding author. Faculty of Social Sciences, University of Tampere, FI-33014. Finland.

E-mail address: irmina.michalek@tuni.fi (I.M. Michalek).
} 


\author{
Abbreviations \\ CE Cumulative exposures \\ CI Confidence intervals \\ IARC International Agency for Research on Cancer \\ NOCCA Nordic Occupational Cancer Study \\ NOCCA-JEM Nordic Occupational Cancer Study Job Exposure \\ Matrix \\ NYK Nordisk Yrkesklassifisering \\ OR Odds ratio \\ UV Ultraviolet
}

exposures to cadmium, lead, welding fumes, and soldering fumes was connected with an elevated risk of kidney cancer in a German population. Pukkala et al. (2009) presented welders as one of the occupations characterized with the highest risk of developing kidney cancer in Nordic males. Recently, the IARC paid attention to associations between exposure to welding fumes and risk of cancer, though bias, chance, and confounding could not be reasonably excluded (Guha et al., 2017). There remains a paucity of evidence on the association between exposure to iron and risk of kidney cancer.

Debate continues about the relative importance of exposure to asbestos, some organic solvents, and pesticides and the risk of kidney cancer (Goodman et al., 1999; Jones et al., 2015; Kleinman et al., 2015; Messing et al., 1994; Ron et al., 1999; Sali and Boffetta, 2000; Wong, 1987; Xie et al., 2016). Recently, elevated risk of kidney cancer was connected with exposures to some types of dusts like glass fibers, mineral wool fibers, and brick dust (Karami et al., 2011). Other causal factors leading to kidney cancer remain speculative.

The primary objective of this study was to assess associations between occupational exposure to heavy metals (chromium (VI), iron, nickel, lead) and welding fumes, and the risk of kidney cancer. The secondary aim was to describe other occupational exposures possibly associated with the risk of kidney cancer.

\section{Materials and methods}

A nested case-control study of individuals from three Nordic countries (Finland, Iceland, and Sweden), who developed kidney cancer from 1961 to 2005, was performed.

\subsection{Source population}

The project was based on the Nordic Occupational Cancer Study (NOCCA) cohort which comprised 14.9 million individuals from five Nordic countries. NOCCA study was described in detail by Pukkala et al. (2009). The study has received approvals from country-specific ethical committees.

\subsection{Study design and participants}

Both cases and controls were extracted from the NOCCA study. The participants in this study were recruited from Finland, Iceland, and Sweden. Norway and Denmark were excluded because of lack of access to the individual level records.

The cases were defined as all individuals diagnosed with cancer of the kidney or the renal pelvis (7th International Classification of Diseases 180) between 1961-2005 in Sweden, 1971-2005 in Finland, and 1982-2004 in Iceland. For each case, five controls were randomly selected from the NOCCA individuals, who were alive and free from kidney cancer on the date of diagnosis of the case (henceforth the "index date" for the case-control set). Controls were individually matched to cases on birth date, sex, and country. Both cancers and controls could have a history of any other comorbid cancer.

\subsection{Source of data on exposure and outcome}

Data on exposure were obtained through population censuses, in which participants were asked to indicate their occupation through free text, using self-administered questionnaires. The following censuses contained information on occupation and were included in the study: Sweden - 1960, 1970, 1980, 1990; Finland - 1970, 1980, 1990; and Iceland - 1981. Participation in the census was mandatory. Subsequently, the data were digitalized and encoded using Nordisk Yrkesklassifisering (NYK), a Nordic adaptation of the International Standard Classification of Occupations from 1958. Data on outcome were acquired from national cancer registers in the respective Nordic countries. Finally, unique personal identity codes were used to perform linkage of the information on occupations from censuses, cancer cases from cancer registries, and death and emigration from national population registries. Only participants with a minimum age of 20 at the index date and having information from at least one census prior to index date were included in this study.

For the purpose of the detailed exposure estimation, NOCCA Job Exposure Matrix (NOCCA-JEM) was used (described in detail by Kauppinen et al. (2009)). The matrix converses NYK codes to quantitative estimates of exposure to 29 substances potentially related to cancer risk (Table 1). For each occupational category, it provides two variables for each agent: the probability of being exposed $(\mathrm{P})$ and the average exposure level (L) among the exposed persons. Time of exposure $(\mathrm{T})$, was assessed individually, starting at the age of 20 (typical age to start work in non-academic occupations), and index date or age of 65 (typical age at retirement), whichever occurred first.

Cumulative occupational exposures (CE) to 29 agents, defined as $P \times L \times T$, were calculated for all cases and controls. The occupation reported during the first census in which the individual took part was considered an occupation performed by this individual from the age of 20 years. When more than one occupational code was assigned to one person in different censuses, it was assumed that the change of work

Table 1

Occupational exposure agents taken into account in the study.

\begin{tabular}{lll}
\hline Abbreviation & Occupational exposure agents & Unit \\
\hline ALHC & Aliphatic and alicyclic hydrocarbon solvents & $\mathrm{ppm}$ \\
ANIM & Animal-borne dust & $\mathrm{mg} / \mathrm{m}^{3}$ \\
ARHC & Aromatic hydrocarbon solvents & $\mathrm{ppm}$ \\
ASB & Asbestos & $\mathrm{f} / \mathrm{cm}^{3}$ \\
BAP & Benzo(a)pyrene & $\mu \mathrm{g} / \mathrm{m}^{3}$ \\
BENZ & Benzene & $\mathrm{ppm}$ \\
BITU & Bitumen fumes & $\mathrm{mg} / \mathrm{m}^{3}$ \\
CHC & Chlorinated hydrocarbon solvents & $\mathrm{ppm}$ \\
CR & Chromium & $\mu \mathrm{m} / \mathrm{m}^{3}$ \\
DEEX & Diesel engine exhaust & $\mathrm{mg} / \mathrm{m}^{3}$ \\
FE & Iron & $\mathrm{mg} / \mathrm{m}^{3}$ \\
FORM & Formaldehyde & $\mathrm{ppm}$ \\
GASO & Gasoline & $\mathrm{ppm}$ \\
IRAD & Ionizing radiation & $\mathrm{mSv}$ \\
MCH & Methylene chloride & $\mathrm{ppm}$ \\
NI & Nickel & $\mu \mathrm{m} / \mathrm{m}^{3}$ \\
NIGH & Nightwork & $\mathrm{none}$ \\
OSOL & Other organic solvents & $\mathrm{ppm}$ \\
PB & Lead & $\mu \mathrm{mol} / 1$ \\
PER & Perchloroethylene & $\mathrm{ppm}$ \\
PPWL & Perceived physical workload & $\mathrm{score}$ \\
QUAR & Quartz dust & $\mathrm{mg} / \mathrm{m}^{3}$ \\
SO2 & Sulphur dioxide & $\mathrm{ppm}$ \\
TCE & 1,1,1-Trichloroethane & $\mathrm{ppm}$ \\
TOLU & Toluene & $\mathrm{ppm}$ \\
TRI & Trichloroethylene & $\mathrm{ppm}$ \\
UV & Ultraviolet radiation & $\mathrm{J} / \mathrm{m}^{2}$ \\
WELD & Welding fumes & $\mathrm{mg} / \mathrm{m}^{3}$ \\
WOOD & Wood dust & $\mathrm{mg} / \mathrm{m}^{3}$ \\
& & \\
& & \\
& &
\end{tabular}

a Score of workers reporting heavy or rather heavy physical work in national Finnish "Quality of Work Life Survey", Finland 1990 (Statistics Finland, 2018). 
occurred in the middle of the period between the censuses. For these individuals, CE was a sum of all $P \times L \times T$, calculated for each separate occupational period. All cumulative exposures were calculated for three different lags of 0,10 , and 20 years, to allow for a cancer latency period. The results for lag 10 and lag 20 were similar, and we therefore only present findings for the lag of 10 years.

\subsection{Statistical analysis}

Conditional logistic regression was used to generate odds ratios (OR) and 95\% confidence intervals (CI), testing the hypothesis that exposure to heavy metals (chromium (VI), iron, lead, and nickel) and welding fumes is associated with increased risk of kidney cancer.

The final main effect model was created using the purposeful selection of variables (explained in detail by Bursac et al. (2008)). The choice of this method of creating the model allows avoiding "overfitting" of the model and generation of numerically unstable estimates.

In the first step, we fitted the univariable logistic regression model for each independent CE variable. Subsequently, we created a first multivariable logistic model in which we fitted all of the covariates for which $p$-value of its Wald statistic was $<0.25$ in the univariable logistic model. The significance level of 0.25 was recommended by Mickey (Mickey and Greenland, 1989). Variables describing heavy metal exposures were forced in the model as a priori selected variables of interest in this study. Next, we assessed the significance of each variable from the multivariable model using the Wald statistic. We gradually eliminated covariates not contributing at the traditional significance level of $p<0.05$. For each reduction, we calculated the difference between the values of the estimated coefficients, $\Delta \beta$. Excluded variables for which $\Delta \beta>20 \%$ were added back into the model. Subsequently, we compared the fit of the first multivariable logistic model with the final one, deploying a likelihood ratio test.

The algorithm denoted aliphatic and alicyclic hydrocarbon solvents, asbestos, chlorinated hydrocarbon solvents, diesel engine exhaust, perceived physical workload, quartz dust, trichloroethylene, ultraviolet radiation, and wood dust, as significant/confounding covariates. Subsequently, correlation check between these agents was performed (Supplemental Fig. 1). Iron and welding fumes were highly correlated, and therefore they were not used in the same model. The final models were as follows: 1) ALHC + ASB + CHC + CR + DEEX + NI + PB + $\mathrm{PPWL}+\mathrm{QUAR}+\mathrm{TRI}+\mathrm{UV}+\mathrm{WELD}+$ WOOD; 2) ALHC + $\mathrm{ASB}+\mathrm{CHC}+\mathrm{CR}+\mathrm{DEEX}+\mathrm{FE}+\mathrm{NI}+\mathrm{PB}+\mathrm{PPWL}+\mathrm{QUAR}+\mathrm{TRI}+\mathrm{UV}$ + WOOD.

Each occupational agent was analyzed as a three-category exposure, including low ( $<50$ percentile), moderate $(\geq 50$ percentile and $<90$ percentile), and high ( $\geq 90$ percentile). Individuals with no exposure (defined as $P \times L \times T=0$ ) constituted a reference category. Subsequently, to assess a dose-response relationship between exposure to heavy metals (chromium (VI), iron, lead, and nickel) and welding fumes, and kidney cancer, Pearson's chi-squared test for linear trend was performed. Unexposed individuals were excluded from the analysis for the trend test. To evaluate the robustness of our inferences a posthoc conservative Bonferroni procedure was adopted for multiple analyses. The Bonferroni-corrected significance threshold was 0.004 (i.e., 0.05/ 13 variables) (Dunn, 1961). We deemed a $p$-value $<0.004$ as significant evidence for a causal association when assessing the significance of trend test.

To explore possible effect modifiers, analyses were later stratified by sex and age group at diagnosis ( $<59,59-74,>74)$. Age groups were $a$ priori determined based on quartile distribution (that is $<$ Q1, Q1Q3, > Q3).

Data management and all analyses were performed using $\mathrm{R}$ studio 1.1.442, using packages corrplot, dosresmeta, Epi, lmtest, readxl, ResourceSelection, survival, and xlsx.
Table 2

Demographic characteristics of the study population.

\begin{tabular}{|c|c|c|c|c|c|c|c|}
\hline \multicolumn{2}{|l|}{ Characteristic } & \multicolumn{2}{|l|}{ Cases } & \multicolumn{2}{|l|}{ Controls } & \multicolumn{2}{|l|}{ Total } \\
\hline & & $\mathrm{N}$ & $\%$ & $\mathrm{~N}$ & $\%$ & $\mathrm{~N}$ & $\%$ \\
\hline Total & & 59,778 & 100.0 & 298,890 & 100.0 & 358,668 & 100.0 \\
\hline \multirow[t]{2}{*}{ Sex } & Male & 34,856 & 58.3 & 174,280 & 58.3 & 209,136 & 58.3 \\
\hline & Female & 24,922 & 41.7 & 124,610 & 41.7 & 149,532 & 41.7 \\
\hline \multirow[t]{3}{*}{ Country } & Finland & 17,647 & 29.5 & 88,235 & 29.5 & 105,882 & 29.5 \\
\hline & Iceland & 588 & 1.0 & 2940 & 1.0 & 3528 & 1.0 \\
\hline & Sweden & 41,543 & 69.5 & 207,715 & 69.5 & 249,258 & 69.5 \\
\hline \multirow[t]{7}{*}{ Year of birth } & $\leq 1910$ & 8992 & 15.0 & 44,960 & 15.0 & 53,952 & 15.0 \\
\hline & $1911-1920$ & 14,660 & 24.5 & 73,300 & 24.5 & 87,960 & 24.5 \\
\hline & 1921-1930 & 16,656 & 27.9 & 83,280 & 27.9 & 99,936 & 27.9 \\
\hline & 1931-1940 & 10,745 & 18.0 & 53,725 & 18.0 & 64,470 & 18.0 \\
\hline & 1941-1950 & 5998 & 10.0 & 29,990 & 10.0 & 35,988 & 10.0 \\
\hline & 1951-1960 & 2399 & 4.0 & 11,995 & 4.0 & 14,394 & 4.0 \\
\hline & $\geq 1961$ & 328 & 0.5 & 1640 & 0.5 & 1968 & 0.5 \\
\hline \multirow{7}{*}{$\begin{array}{l}\text { Age at index } \\
\text { date }\end{array}$} & $20-29$ & 94 & 0.2 & 474 & 0.2 & 568 & 0.2 \\
\hline & $30-39$ & 792 & 1.3 & 3971 & 1.3 & 4763 & 1.3 \\
\hline & $40-49$ & 4257 & 7.1 & 21,296 & 7.1 & 25,553 & 7.1 \\
\hline & $50-59$ & 11,756 & 19.7 & 58,749 & 19.7 & 70,505 & 19.7 \\
\hline & $60-69$ & 18,499 & 30.9 & 92,338 & 30.9 & 110,837 & 30.9 \\
\hline & 70-79 & 17,846 & 29.9 & 89,276 & 29.9 & 107,122 & 29.9 \\
\hline & $\geq 80$ & 6534 & 10.9 & 32,786 & 11.0 & 39,320 & 11.0 \\
\hline
\end{tabular}

\section{Results}

In the study, 59,778 kidney cancer cases, and 298,890 sex-, age-, and country-matched controls were identified (Table 2). Males accounted for $58.3 \%$ of study participants, and females for $41.7 \%$. Most individuals were born before 1940 . The mean age at the diagnosis was 66 years (median 67 years).

\subsection{Heavy metals and welding fumes}

In the OR analysis for both sexes and all age groups (Table 3), for none of the studied agents, the dose-response trend was statistically significant. It was observed that ORs in women were frequently higher than in men although based on a much smaller number of cases (Table 4). Moreover, moderate and high exposures to welding fumes were associated with excess risk in men. This may still not indicate that the absolute excess risk due to the exposure would be higher in women because the reference incidence level of kidney cancer is much lower in women. In the analysis with stratification by age at the index date (Table 5), in the group of $<59$ years, OR for high exposure to nickel was significant (OR 1.49, 95\%CI 1.03-2.17). In the group of 59-74 years, ORs for the following were statistically significant: high exposure to iron (OR 1.41, 95\%CI 1.07-1.85), moderate exposure to welding fumes (OR 1.27, 95\%CI 1.02-1.56), and high exposure to welding fumes (OR 1.43, 95\%CI 1.09-1.89).

\subsection{Other exposures}

Further analysis of covariates revealed a statistically significant increase of OR for high exposure to asbestos (OR 1.19, 95\%CI 1.08-1.31). Statistically significant (more than $10 \%$ ) decrease of OR was observed among individuals characterized with high exposure to aliphatic and alicyclic hydrocarbon solvents (OR 0.81, 95\%CI 0.69-0.95); high exposure to perceived physical workload (OR 0.86 , 95\%CI $0.82-0.91$ ); moderate (OR 0.85 , 95\%CI $0.81-0.88$ ), and high exposure (OR 0.85 , $95 \%$ CI $0.79-0.92$ ) to ultraviolet (UV) radiation; and high (OR 0.82 , 95\%CI 0.71-0.94) exposure to wood dust. Dose-response test for trend was statistically significant for exposure to UV $(p<0.001)$. 
Table 3

Odds ratios (OR) and 95\% Confidence intervals (95\% CI) of kidney cancer associated with occupational exposures.

\begin{tabular}{|c|c|c|c|c|c|c|}
\hline Agent (unit) & Cumulative exposure & Cases & Controls & OR & $95 \% \mathrm{CI}$ & $p$-value for trend \\
\hline \multicolumn{7}{|l|}{ Heavy metals and welding fumes } \\
\hline \multirow[t]{4}{*}{ Chromium $^{\mathrm{b}}\left(\mu \mathrm{g} / \mathrm{m}^{3}\right.$-years $)$} & unexposed & 53,272 & 268,143 & 1.00 & Ref & 0.78 \\
\hline & $<1331.05$ & 3248 & 15,379 & 0.99 & $0.91-1.09$ & \\
\hline & $1331.05-13,611.17$ & 2647 & 12,253 & 1.07 & $0.96-1.18$ & \\
\hline & $>13,611.17$ & 611 & 3115 & 0.99 & $0.86-1.15$ & \\
\hline \multirow[t]{4}{*}{$\operatorname{Iron}^{\mathrm{b}}$ (mg/m $\mathrm{m}^{3}$-years $)$} & unexposed & 54,153 & 273,058 & 1.00 & Ref & 0.36 \\
\hline & $<410.84$ & 2841 & 12,887 & 1.09 & $0.94-1.27$ & \\
\hline & $410.84-4899.30$ & 2206 & 10,377 & 1.10 & $0.95-1.28$ & \\
\hline & $>4899.30$ & 578 & 2568 & 1.15 & $0.94-1.39$ & \\
\hline \multirow[t]{4}{*}{ Nickel ${ }^{\mathrm{b}}\left(\mu \mathrm{g} / \mathrm{m}^{3}\right.$-years $)$} & unexposed & 54,074 & 272,532 & 1.00 & Ref & 0.57 \\
\hline & $<992.80$ & 2859 & 13,227 & 0.92 & $0.80-1.06$ & \\
\hline & $992.80-5624.32$ & 2266 & 10,503 & 0.90 & $0.78-1.04$ & \\
\hline & $>5624.32$ & 579 & 2628 & 0.99 & $0.82-1.20$ & \\
\hline \multirow[t]{4}{*}{ Lead $^{\mathrm{b}}$ ( $\mu \mathrm{mol} / \mathrm{l}$-years $)$} & unexposed & 52,154 & 263,218 & 1.00 & Ref & 0.58 \\
\hline & $<369.53$ & 3874 & 17,776 & 1.09 & $1.03-1.16$ & \\
\hline & $369.53-1151.97$ & 3040 & 14,276 & 1.06 & $0.99-1.13$ & \\
\hline & $>1151.97$ & 710 & 3620 & 0.95 & $0.86-1.05$ & \\
\hline \multirow[t]{4}{*}{ Welding fumes ${ }^{\mathrm{a}}\left(\mathrm{mg} / \mathrm{m}^{3}\right.$-years $)$} & unexposed & 54,154 & 273,062 & 1.00 & Ref & 0.27 \\
\hline & $<254.00$ & 2756 & 12,970 & 1.05 & $0.90-1.22$ & \\
\hline & $254.00-12,281.40$ & 2281 & 10,300 & 1.14 & $0.98-1.33$ & \\
\hline & $>12,281.40$ & 587 & 2558 & 1.20 & $0.99-1.46$ & \\
\hline \multicolumn{7}{|l|}{ Other exposures } \\
\hline \multirow[t]{4}{*}{ Aliphatic and alicyclic hydrocarbon solvents ${ }^{\mathrm{b}}$ (ppm-years) } & unexposed & 56,679 & 284,102 & 1.00 & Ref & 0.50 \\
\hline & $<1740.45$ & 1628 & 7316 & 1.01 & $0.93-1.09$ & \\
\hline & $1740.45-30,000.62$ & 1223 & 5931 & 0.99 & $0.90-1.08$ & \\
\hline & $>30,000.62$ & 248 & 1541 & 0.81 & $0.69-0.95$ & \\
\hline \multirow[t]{4}{*}{ Asbestos $^{\mathrm{b}}$ (f/ $\mathrm{cm}^{3}$-years) } & unexposed & 50,693 & 253,982 & 1.00 & Ref & 0.36 \\
\hline & $<192.41$ & 4486 & 22,513 & 0.97 & $0.93-1.01$ & \\
\hline & $192.41-1628.47$ & 3646 & 17,947 & 1.04 & $0.98-1.10$ & \\
\hline & $>1628.47$ & 953 & 4448 & 1.19 & $1.08-1.31$ & \\
\hline \multirow[t]{4}{*}{ Chlorinated hydrocarbon solvents ${ }^{\mathrm{b}}$ (ppm-years) } & unexposed & 58,461 & 292,116 & 1.00 & Ref & 0.71 \\
\hline & $<2233.27$ & 702 & 3344 & 1.05 & $0.95-1.16$ & \\
\hline & $2233.27-5779.19$ & 490 & 2746 & 0.93 & $0.80-1.07$ & \\
\hline & $>5779.19$ & 125 & 684 & 0.89 & $0.70-1.13$ & \\
\hline \multirow[t]{4}{*}{ Diesel engine exhaust ${ }^{\mathrm{b}}$ (mg/m ${ }^{3}$-years) } & unexposed & 52,487 & 265,786 & 1.00 & Ref & 0.07 \\
\hline & $<66.00$ & 3692 & 16,869 & 1.08 & $1.03-1.12$ & \\
\hline & $66.00-197.39$ & 2863 & 12,931 & 1.07 & $1.02-1.12$ & \\
\hline & $>197.39$ & 736 & 3304 & 1.07 & $0.98-1.17$ & \\
\hline \multirow[t]{4}{*}{ Perceived physical workload ${ }^{\mathrm{b}}$ (score ${ }^{\mathrm{c}}$-years) } & unexposed & 26,320 & 127,620 & 1.00 & Ref & 0.06 \\
\hline & $<418.66$ & 17,375 & 84,989 & 0.99 & $0.97-1.02$ & \\
\hline & $418.66-1600.14$ & 13,151 & 68,740 & 0.97 & $0.94-1.00$ & \\
\hline & $>1600.14$ & 2932 & 17,541 & 0.86 & $0.82-0.91$ & \\
\hline \multirow[t]{4}{*}{ Quartz dust ${ }^{\mathrm{b}}$ (mg/m ${ }^{3}$-years) } & unexposed & 55,905 & 278,965 & 1.00 & Ref & 0.98 \\
\hline & $<126.85$ & 1932 & 9967 & 1.04 & $0.98-1.12$ & \\
\hline & $126.85-640.53$ & 1567 & 7952 & 1.03 & $0.95-1.10$ & \\
\hline & $>640.53$ & 374 & 2006 & 0.91 & $0.79-1.03$ & \\
\hline \multirow[t]{4}{*}{ Trichloroethylene ${ }^{\mathrm{b}}$ (ppm-years) } & unexposed & 56,316 & 282,593 & 1.00 & Ref & 0.61 \\
\hline & $<3192.54$ & 1760 & 8118 & 1.00 & $0.94-1.07$ & \\
\hline & $3192.54-12785.08$ & 1347 & 6560 & 0.92 & $0.85-1.00$ & \\
\hline & $>12,785.08$ & 355 & 1619 & 1.03 & $0.88-1.19$ & \\
\hline \multirow[t]{4}{*}{ Ultraviolet radiation ${ }^{\mathrm{b}}\left(\mathrm{J} / \mathrm{m}^{2}\right.$-years $)$} & unexposed & 46,077 & 224,064 & 1.00 & Ref & $<0.001$ \\
\hline & $<464,202.10$ & 7140 & 37,124 & 0.94 & $0.91-0.97$ & \\
\hline & $464,202.10-860,940.90$ & 5213 & 30,198 & 0.85 & $0.81-0.88$ & \\
\hline & $>860,940.90$ & 1348 & 7504 & 0.85 & $0.79-0.92$ & \\
\hline \multirow[t]{4}{*}{ Wood dust ${ }^{\mathrm{b}}$ (mg/m ${ }^{3}$-years) } & unexposed & 57,138 & 284,698 & 1.00 & Ref & 0.10 \\
\hline & $<923.70$ & 1334 & 7082 & 0.95 & $0.89-1.02$ & \\
\hline & $923.70-3675.15$ & 1062 & 5670 & 0.92 & $0.85-0.99$ & \\
\hline & $>3675.15$ & 244 & 1440 & 0.82 & $0.71-0.94$ & \\
\hline
\end{tabular}

a OR estimates calculated using Model 2.

b OR estimates calculated using Model 1.

c Score of workers reporting heavy or rather heavy physical work in national Finnish "Quality of Work Life Survey", Finland 1990 (Statistics Finland, 2018 ).

\section{Discussion}

\subsection{Heavy metals and welding fumes}

This study was unable to demonstrate any significant dose-dependent relationship between exposures to chromium (VI), iron, nickel, lead, and welding fumes and the risk of developing kidney cancer. Among individuals diagnosed under the age of 59 years, a link may exist between exposure to nickel and risk of kidney cancer. The value of
ORs among the individuals diagnosed between the age of 59 and 74, and characterized by moderate and high CE to welding fumes, and high $\mathrm{CE}$ to iron, suggests that a weak link may exist between exposure to welding fumes or iron, and risk of developing kidney cancer. Concurrent exposure to iron and welding fumes hinders understanding of their independent roles as risk factors. In the case of the other ORs identified in the study (low CE to lead), we cannot exclude the possibility of chance findings.

One of the issues that emerge from the findings of the present study 
Table 4

Sex-specific odds ratios (OR) and 95\% Confidence intervals (95\% CI) of kidney cancer associated with exposures to heavy metals and welding fumes.

\begin{tabular}{|c|c|c|c|c|c|c|c|c|c|c|c|}
\hline \multirow[t]{2}{*}{ Agent (unit) } & \multirow[t]{2}{*}{ Cumulative exposure } & \multicolumn{5}{|l|}{ Males } & \multicolumn{5}{|l|}{ Females } \\
\hline & & Cases & Controls & OR & $95 \% \mathrm{CI}$ & $p$-value for trend & Cases & Controls & OR & $95 \% \mathrm{CI}$ & $p$-value for trend \\
\hline \multirow[t]{4}{*}{ Chromium ${ }^{\mathrm{b}}$ ( $\mu \mathrm{g} / \mathrm{m}^{3}$-years $)$} & unexposed & 28,805 & 145,488 & 1.00 & Ref & 0.55 & 24,467 & 122,655 & 1.00 & Ref & 0.55 \\
\hline & $<1331.05$ & 3004 & 14,314 & 1.00 & $0.91-1.11$ & & 244 & 1065 & 0.93 & $0.69-1.25$ & \\
\hline & 1331.05-13,611.17 & 2462 & 11,467 & 1.10 & $0.98-1.23$ & & 185 & 786 & 0.84 & $0.59-1.21$ & \\
\hline & $>13,611.17$ & 585 & 3011 & 1.04 & $0.89-1.22$ & & 26 & 104 & 0.74 & $0.39-1.41$ & \\
\hline \multirow[t]{4}{*}{ Iron ${ }^{b}$ (mg/m ${ }^{3}$-years) } & unexposed & 29,578 & 149,845 & 1.00 & Ref & 0.31 & 24,575 & 123,213 & 1.00 & Ref & 0.72 \\
\hline & $<410.84$ & 2607 & 11,956 & 1.09 & $0.93-1.28$ & & 234 & 931 & 1.34 & $0.73-2.48$ & \\
\hline & $410.84-4899.30$ & 2101 & 9935 & 1.14 & $0.98-1.33$ & & 105 & 442 & 1.09 & $0.57-2.09$ & \\
\hline & $>4899.30$ & 570 & 2544 & 1.16 & $0.95-1.42$ & & 8 & 24 & 1.37 & $0.40-4.69$ & \\
\hline \multirow[t]{4}{*}{ Nickel $^{\mathrm{b}}\left(\mu \mathrm{g} / \mathrm{m}^{3}\right.$-years $)$} & unexposed & 29,527 & 149,453 & 1.00 & Ref & 0.42 & 24,547 & 123,079 & 1.00 & Ref & 0.82 \\
\hline & $<992.80$ & 2620 & 12,210 & 0.92 & $0.79-1.06$ & & 239 & 1017 & 0.79 & $0.46-1.33$ & \\
\hline & $992.80-5624.32$ & 2149 & 10,054 & 0.87 & $0.75-1.02$ & & 117 & 449 & 1.12 & $0.65-1.94$ & \\
\hline & $>5624.32$ & 560 & 2563 & 0.93 & $0.76-1.14$ & & 19 & 65 & 1.49 & $0.60-3.70$ & \\
\hline \multirow[t]{4}{*}{ Lead $^{\mathrm{b}}$ ( $\mu$ mol/1-years $)$} & unexposed & 27,897 & 141,415 & 1.00 & Ref & 0.78 & 24,257 & 121,803 & 1.00 & Ref & 0.87 \\
\hline & $<369.53$ & 3427 & 15,978 & 1.07 & $1.00-1.15$ & & 447 & 1798 & 1.17 & $0.99-1.39$ & \\
\hline & $369.53-1151.97$ & 2860 & 13,455 & 1.05 & $0.98-1.13$ & & 180 & 821 & 0.99 & $0.79-1.25$ & \\
\hline & $>1151.97$ & 672 & 3432 & 0.94 & $0.85-1.04$ & & 38 & 188 & 0.83 & $0.54-1.29$ & \\
\hline \multirow[t]{4}{*}{ Welding fumes ${ }^{\mathrm{a}}$ ( $\mathrm{mg} / \mathrm{m}^{3}$-years) } & unexposed & 29,579 & 149,849 & 1.00 & Ref & 0.24 & 24,575 & 123,213 & 1.00 & Ref & 0.63 \\
\hline & $<254.00$ & 2485 & 11,877 & 1.06 & $0.91-1.24$ & & 271 & 1093 & 1.25 & $0.69-2.29$ & \\
\hline & $254.00-12,281.40$ & 2211 & 10,014 & 1.17 & $1.00-1.36$ & & 70 & 286 & 1.29 & $0.65-2.55$ & \\
\hline & $>12,281.40$ & 581 & 2540 & 1.22 & $0.99-1.49$ & & 6 & 18 & 1.42 & $0.35-5.87$ & \\
\hline
\end{tabular}

a OR estimates calculated using Model 2.

b OR estimates calculated using Model 1.

is the weak association between exposure to welding fumes and the risk of kidney cancer. This accords both with our earlier observations (Michalek et al., 2018a, 2018b) and those of MacLeod et al. (2017). Furthermore, this finding is in line with the position of the IARC (IARC, 2006). In our study, the definition of welders encompassed individuals who join and cut metal parts using flame, electric arc, and other sources of heat to melt and cut or fuse metal. Exposures of welders may differ depending on their actual work.Therefore, it would be good if the NOCCA-JEM, like its Finnish equivalent FINJEM, would include exposure estimates for combinations of occupation and industry (e.g. "welder in stainless steel industry"; see Kauppinen et al., 1998). Unfortunately, we did not have access to industry codes for all Nordic countries. The known occupational exposures among welders are fumes, gases, UV radiation, electromagnetic fields, and coexposure to asbestos and solvents (Guha et al., 2017). Further studies, which take these variables into account, will need to be undertaken.

The observed higher ORs among females exposed to iron and welding fumes might suggest possible higher biological susceptibility of the female kidney to metals, which was already suggested in the literature (Johnson et al., 2003). However, it is challenging to demonstrate sound sex differences even in such a large study due to the very few women ever employed as a welder, smelter, furnacemen, plumbers, and other metal industry workers. We should also avoid direct comparison of the relative risk estimates between sexes as the incidence of kidney cancer in unexposed women used as the reference is much lower than in men.

Prior studies noted the importance of exposure to lead (Boffetta et al., 2011; Ilychova and Zaridze, 2012). However, the findings of the current study do not support the previous research. There are several possible explanations for this inconsistency. One of them might be the fact that the previous studies were based on small study populations. This inconsistency may also be due to the fact that the regression models in the previous studies included a little number of variables of interest. It could be argued that the positive results in those studies were caused by the fact that no covariates were included.

For the purpose of the discussion, we created one more set of two conditional logistic regression models in which we included only heavy metals and welding fumes, i.e., S1) CR + NI + PB + WELD, and S2) $\mathrm{CR}+\mathrm{FE}+\mathrm{NI}+\mathrm{PB}$. These experiments were designed to estimate what effect heavy metals and welding fumes would have on ORs if they were the only occupational exposure factors included in the final multivariable model, that is, data for only five occupational agents instead of 29 would be available. These experiments confirmed that for smaller models that do not include other covariates, ORs are mostly higher (Supplemental Table 1).

Findings on no association between the exposure to chromium (VI) and the risk of kidney cancer are consistent with the literature (Boffetta et al., 2011; Langard, 1994). Very little was found in the literature on the question of exposures to iron or nickel and the risk of kidney cancer.

In our study, we were unable to examine the possible association between occupational exposure to cadmium and risk of kidney cancer because estimates for cadmium exposure are not included in the NOCCA-JEM. The importance of this metal regarding kidney toxicity due to its estrogenic nature was broadly discussed in the literature (Johnson et al., 2003) in the context of the estrogenic features of the kidney (Maric, 2009).

\subsection{Other covariates}

The results of this study indicate that there is a positive association between exposure to asbestos and the risk of kidney cancer. This study supports evidence from previous observations (Peters et al., 2018a, b; Sali and Boffetta, 2000). Furthermore, we found an increased risk of developing kidney cancer among individuals exposed to diesel engine exhaust. This finding was also reported by Peters et al. (Peters et al., 2018a, b) and Boffetta et al. (2001).

In this study, the physical workload was found to be associated with a lower risk of kidney cancer. These results are likely to be related to findings, that obesity may be associated with a higher risk of kidney malignancies (Ildaphonse et al., 2009; Mathew et al., 2009; Sawada et al., 2010).

Exposure to wood dust was found to be associated with a decreased risk of developing kidney cancer. Full understanding of how wood dust contributes to the risk of kidney cancer is still lacking. It was reported that the standardized incidence ratio was lower among woodworkers (Pukkala et al., 2009). However, these results need to be interpreted with caution as there is a positive correlation between exposure to wood dust and exposure to perceived physical workload (Supplemental Fig. 1), which is inversely correlated with the risk of obesity, that is a recognized risk factor of kidney cancer. 
Table 5

Odds ratios (OR) and 95\% Confidence intervals (95\% CI) of kidney cancer associated with exposures to heavy metals and welding fumes, by age at index date.

\begin{tabular}{|c|c|c|c|c|c|c|}
\hline Agent (unit) & Cumulative exposure & Cases & Controls & OR & $95 \% \mathrm{CI}$ & $p$-value for trend \\
\hline \multicolumn{7}{|l|}{ Age at index date $<59$ years } \\
\hline \multirow[t]{4}{*}{ Chromium ${ }^{\mathrm{b}}\left(\mu \mathrm{g} / \mathrm{m}^{3}\right.$-years $)$} & & 13,239 & 66,963 & 1.00 & Ref & 0.83 \\
\hline & $<1331.05$ & 1183 & 5365 & 1.08 & $0.91-1.28$ & \\
\hline & $1331.05-13,611.17$ & 827 & 3862 & 1.06 & $0.88-1.28$ & \\
\hline & $>13,611.17$ & 79 & 387 & 0.93 & $0.66-1.30$ & \\
\hline \multirow{4}{*}{ Iron ${ }^{b}\left(\mathrm{mg} / \mathrm{m}^{3}\right.$-years $)$} & unexposed & 13,508 & 68,356 & 1.00 & Ref & 0.91 \\
\hline & $<410.84$ & 1125 & 4958 & 0.95 & $0.71-1.26$ & \\
\hline & $410.84-4899.30$ & 623 & 2940 & 0.97 & $0.72-1.29$ & \\
\hline & $>4899.30$ & 72 & 323 & 1.01 & $0.62-1.63$ & \\
\hline \multirow[t]{4}{*}{ Nickel ${ }^{\mathrm{b}}\left(\mu \mathrm{g} / \mathrm{m}^{3}\right.$-years $)$} & unexposed & 13,470 & 68,181 & 1.00 & Ref & 0.50 \\
\hline & $<992.80$ & 1246 & 5549 & 1.04 & $0.80-1.34$ & \\
\hline & $992.80-5624.32$ & 485 & 2329 & 1.01 & $0.77-1.32$ & \\
\hline & $>5624.32$ & 127 & 518 & 1.49 & $1.03-2.17$ & \\
\hline \multirow[t]{4}{*}{ Lead ${ }^{\mathrm{b}}$ ( $\mu$ mol/1-years) } & unexposed & 12,876 & 65,278 & 1.00 & Ref & 0.74 \\
\hline & $<369.53$ & 1683 & 7722 & 1.05 & $0.95-1.17$ & \\
\hline & $369.53-1151.97$ & 690 & 3211 & 1.02 & $0.90-1.15$ & \\
\hline & $>1151.97$ & 79 & 366 & 1.06 & $0.80-1.42$ & \\
\hline \multirow[t]{4}{*}{ Welding fumes ${ }^{a}\left(\mathrm{mg} / \mathrm{m}^{3}\right.$-years $)$} & unexposed & 13,508 & 68,356 & 1.00 & Ref & 0.88 \\
\hline & $<254.00$ & 1086 & 4975 & 0.92 & $0.69-1.22$ & \\
\hline & $254.00-12,281.40$ & 622 & 2757 & 1.01 & $0.76-1.35$ & \\
\hline & $>12,281.40$ & 112 & 489 & 1.15 & $0.77-1.74$ & \\
\hline \multicolumn{7}{|l|}{ Age at index date $59-74$ years } \\
\hline \multirow[t]{4}{*}{ Chromium ${ }^{\mathrm{b}}$ ( $\mu \mathrm{g} / \mathrm{m}^{3}$-years $)$} & unexposed & 24,892 & 125,119 & 1.00 & Ref & 0.96 \\
\hline & $<1331.05$ & 1474 & 7187 & 0.95 & $0.83-1.09$ & \\
\hline & $1331.05-13,611.17$ & 1313 & 6063 & 1.06 & $0.92-1.23$ & \\
\hline & $>13,611.17$ & 297 & 1569 & 0.94 & $0.75-1.17$ & \\
\hline \multirow[t]{4}{*}{ Iron $^{\mathrm{b}}$ (mg/m $\mathrm{m}^{3}$-years $)$} & unexposed & 25,318 & 127,525 & 1.00 & Ref & 0.15 \\
\hline & $<410.84$ & 1297 & 6047 & 1.22 & $0.98-1.52$ & \\
\hline & $410.84-4899.30$ & 1026 & 4855 & 1.22 & $0.98-1.51$ & \\
\hline & $>4899.30$ & 335 & 1511 & 1.41 & $1.07-1.85$ & \\
\hline \multirow[t]{4}{*}{ Nickel ${ }^{\mathrm{b}}\left(\mu \mathrm{g} / \mathrm{m}^{3}\right.$-years $)$} & unexposed & 25,293 & 127,281 & 1.00 & Ref & 0.23 \\
\hline & $<992.80$ & 1196 & 5741 & 0.83 & $0.68-1.02$ & \\
\hline & $992.80-5624.32$ & 1187 & 5455 & 0.85 & $0.69-1.04$ & \\
\hline & $>5624.32$ & 300 & 1461 & 0.77 & $0.58-1.02$ & \\
\hline \multirow[t]{4}{*}{ Lead $^{\mathrm{b}}$ ( $\mu$ mol/l-years $)$} & unexposed & 24,370 & 122,861 & 1.00 & Ref & 0.67 \\
\hline & $<369.53$ & 1624 & 7524 & 1.09 & $1.00-1.20$ & \\
\hline & $369.53-1151.97$ & 1652 & 7889 & 1.05 & $0.95-1.15$ & \\
\hline & $>1151.97$ & 330 & 1664 & 0.98 & $0.84-1.13$ & \\
\hline \multirow[t]{4}{*}{ Welding fumes ${ }^{\mathrm{a}}$ ( $\mathrm{mg} / \mathrm{m}^{3}$-years) } & unexposed & 25,319 & 127,527 & 1.00 & Ref & 0.13 \\
\hline & $<254.00$ & 1200 & 5767 & 1.14 & $0.92-1.42$ & \\
\hline & $254.00-12,281.40$ & 1133 & 5190 & 1.27 & $1.02-1.56$ & \\
\hline & $>12,281.40$ & 324 & 1454 & 1.43 & $1.09-1.89$ & \\
\hline \multicolumn{7}{|l|}{ Age at index date $>74$ years } \\
\hline \multirow[t]{4}{*}{ Chromium ${ }^{\mathrm{b}}\left(\mu \mathrm{g} / \mathrm{m}^{3}\right.$-years $)$} & unexposed & 15,141 & 76,061 & 1.00 & Ref & 0.89 \\
\hline & $<1331.05$ & 591 & 2827 & 0.96 & $0.78-1.17$ & \\
\hline & $1331.05-13,611.17$ & 507 & 2328 & 1.04 & $0.81-1.33$ & \\
\hline & $>13,611.17$ & 235 & 1159 & 1.06 & $0.78-1.43$ & \\
\hline Iron $^{b}$ ( $\mathrm{mg} / \mathrm{m}^{3}$-years) & unexposed & 15,327 & 77,177 & 1.00 & Ref & 1.00 \\
\hline & $<410.84$ & 419 & 1882 & 1.02 & $0.73-1.44$ & \\
\hline & $410.84-4899.30$ & 557 & 2582 & 1.03 & $0.75-1.41$ & \\
\hline & $>4899.30$ & 171 & 734 & 0.96 & $0.63-1.44$ & \\
\hline Nickel ${ }^{\mathrm{b}}\left(\mu \mathrm{g} / \mathrm{m}^{3}\right.$-years $)$ & unexposed & 15,311 & 77,070 & 1.00 & Ref & 0.94 \\
\hline & $<992.80$ & 417 & 1937 & 0.96 & $0.70-1.30$ & \\
\hline & $992.80-5624.32$ & 594 & 2719 & 0.97 & $0.72-1.30$ & \\
\hline & $>5624.32$ & 152 & 649 & 1.13 & $0.75-1.70$ & \\
\hline Lead ${ }^{\mathrm{b}}$ ( $\mu$ mol/1-years) & unexposed & 14,908 & 75,079 & 1.00 & Ref & 0.67 \\
\hline & $<369.53$ & 567 & 2530 & 1.17 & $1.01-1.36$ & \\
\hline & $369.53-1151.97$ & 698 & 3176 & 1.16 & $0.99-1.35$ & \\
\hline & $>1151.97$ & 301 & 1590 & 0.94 & $0.80-1.12$ & \\
\hline Welding fumes ${ }^{a}$ ( $\mathrm{mg} / \mathrm{m}^{3}$-years) & unexposed & 15,327 & 77,179 & 1.00 & Ref & 0.95 \\
\hline & $<254.00$ & 470 & 2228 & 0.95 & $0.68-1.34$ & \\
\hline & $254.00-12,281.40$ & 526 & 2353 & 1.08 & $0.79-1.49$ & \\
\hline & $>12,281.40$ & 151 & 615 & 0.98 & $0.63-1.51$ & \\
\hline
\end{tabular}

a OR estimates calculated using Model 2.

b OR estimates calculated using Model 1.

Finally, an unanticipated finding was that exposure to UV radiation was associated with a lower risk of kidney malignancies. A dose-response effect was confirmed with the test for trend. A possible explanation for this might be an increased level of vitamin $\mathrm{D}$ due to sunlight exposure. These results corroborate ideas of Darling et al.
(2016). Here, again, a note of caution is due since a positive correlation between exposure to UV radiation and exposure to perceived physical workload exists (Supplemental Fig. 1). Physical activity decreases the risk of obesity, that is one of the recognized risk factors of kidney cancer. 


\subsection{Strengths and limitations of the study}

To the knowledge of the authors, this is the first study to assess the relationship between exposure to heavy metals and welding fumes deploying whole national populations. The high number of kidney cancer cases $(59,778)$ is the main strength of our study.

Additional advantages are the linkage based on unique personal identity codes and the accuracy of occupational coding. The method of the linkage, by definition, ensured a complete ascertainment of relevant events. Moreover, according to Pukkala et al. (2018), close to $100 \%$ coverage of incident cases has been reported in each of the registries.

Findings of our study may be somewhat limited by the lack of data regarding tobacco smoking. However, a study adjusting the incidence of lung cancer for smoking (Haldorsen et al., 2004) supported clarification that the differing smoking patterns do not explain all the occupational variation in risk. Other known risk factors for renal cancer not taken into consideration in our research are hereditary tumors, such as von Hippel-Lindau syndrome.

Another source of uncertainty is limited data on professional history which was assessed only during censuses. We had to assume that there were no changes between the age of 20 years and the earliest known census occupation, nor between the latest known census occupation and age of 65 years.

\section{Conclusions}

In conclusion, in our study, there was no association between exposure to chromium (VI) or lead and the risk of kidney cancer. Multiple regression analysis revealed that there is an elevated risk of kidney cancer under the age of 59 in individuals with high exposure to nickel. Moreover, among individuals diagnosed with kidney cancer at the age of 59-74, the risk was elevated for high exposure to iron, and moderate and high exposure to welding fumes. Concurrent exposure to the latter agents may hinder interpretation of their roles as independent risk factors.

\section{Conflicts of interest}

The authors declare they have no actual or potential competing financial interests.

\section{Appendix A. Supplementary data}

Supplementary data to this article can be found online at https:// doi.org/10.1016/j.envres.2019.03.023.

\section{Sources of funding}

This research did not receive any specific grant from funding agencies in the public, commercial, or not-for-profit sectors.

\section{References}

Boffetta, P., Dosemeci, M., Gridley, G., Bath, H., Moradi, T., Silverman, D., 2001. Occupational exposure to diesel engine emissions and risk of cancer in Swedish men and women. Cancer Causes Control 12 (4), 365-374.

Boffetta, P., Fontana, L., Stewart, P., Zaridze, D., Szeszenia-Dabrowska, N., Janout, V., et al., 2011. Occupational exposure to arsenic, cadmium, chromium, lead and nickel, and renal cell carcinoma: a case-control study from Central and Eastern Europe Occup. Environ. Med. 68 (10), 723-728.

Bursac, Z., Gauss, C.H., Williams, D.K., Hosmer, D.W., 2008. Purposeful selection of variables in logistic regression. Source Code Biol. Med. 3, 17.

Darling, A.L., Abar, L., Norat, T., 2016. WCRF-AICR continuous update project: systematic literature review of prospective studies on circulating 25-hydroxyvitamin D and kidney cancer risk. J. Steroid Biochem. Mol. Biol. 164, 85-89.

Dunn, O.J., 1961. Multiple comparisons among means. J. Am. Stat. Assoc. 56 (293), 52-64.

Goodman, M., Morgan, R.W., Ray, R., Malloy, C.D., Zhao, K., 1999. Cancer in asbestosexposed occupational cohorts: a meta-analysis. Cancer Causes Control 10 (5), 453-465.
Guha, N., Loomis, D., Guyton, K.Z., Grosse, Y., El Ghissassi, F., Bouvard, V., et al., 2017. Carcinogenicity of welding, molybdenum trioxide, and indium tin oxide. Lancet Oncol. 18 (5), 581-582.

Haldorsen, T., Andersen, A., Boffetta, P., 2004. Smoking-adjusted incidence of lung cancer by occupation among Norwegian men. Cancer Causes Control 15 (2), $139-147$.

IARC WHO, 2006. IARC Monographs on Evaluation of Carcinogenic Risk to Humans. WHO. IARC, Lyon, France.

Ildaphonse, G., George, P.S., Mathew, A., 2009. Obesity and kidney cancer risk in men: a meta-analysis (1992-2008). Asian Pac. J. Cancer Prev. 10 (2), 279-286.

Ilychova, S.A., Zaridze, D.G., 2012. Cancer mortality among female and male workers occupationally exposed to inorganic lead in the printing industry. Occup. Environ. Med. 69 (2), 87-92.

Johnson, M.D., Kenney, N., Stoica, A., Hilakivi-Clarke, L., Singh, B., Chepko, G., et al., 2003 Aug. Cadmium mimics the in vivo effects of estrogen in the uterus and mammary gland. Nat. Med. 9 (8), 1081-1084.

Jones, R.R., Barone-Adesi, F., Koutros, S., Lerro, C.C., Blair, A., Lubin, J., et al., 2015. Incidence of solid tumours among pesticide applicators exposed to the organophosphate insecticide diazinon in the Agricultural Health Study: an updated analysis. Occup. Environ. Med. 72 (7), 496-503.

Karami, S., Boffetta, P., Stewart, P.S., Brennan, P., Zaridze, D., Matveev, V., et al., 2011. Occupational exposure to dusts and risk of renal cell carcinoma. May 24. Br. J. Canc. 104 (11), 1797-1803.

Kauppinen, T., Heikkila, P., Plato, N., Woldbaek, T., Lenvik, K., Hansen, J., et al., 2009. Construction of job-exposure matrices for the nordic occupational cancer study (NOCCA). Acta Oncol. 48 (5), 791-800.

Kauppinen, T., Toikkanen, J., Pukkala, E., 1998 Apr. From cross-tabulations to multipurpose exposure information systems: a new job-exposure matrix. Am. J. Ind. Med. 33 (4), 409-417.

Kleinman, E.J., Christos, P.J., Gerber, L.M., Reilly, J.P., Moran, W.F., Einstein, A.J., et al., 2015. NYPD cancer incidence rates 1995-2014 encompassing the entire World Trade Center Cohort. J. Occup. Environ. Med. 57 (10), e101-e113.

Langard, S., 1994. Nickel-related cancer in welders. Sci. Total Environ. 148 (2-3), 303-309.

MacLeod, J.S., Harris, M.A., Tjepkema, M., Peters, P.A., Demers, P.A., 2017. Cancer risks among welders and occasional welders in a national population-based cohort study: Canadian Census Health and Environmental Cohort. Saf Health Work 8 (3), 258-266.

Maric, C., 2009 Apr. Sex, diabetes and the kidney. Am. J. Physiol. Renal. Physiol. 296 (4), F680-F688.

Mathew, A., George, P.S., Ildaphonse, G., 2009. Obesity and kidney cancer risk in women: a meta-analysis (1992-2008). Asian Pac. J. Cancer Prev. 10 (3), 471-478.

Messing, R.B., Gust, L.D., Petersen, D.W., 1994. Carcinogenicity of chloroform. Science 264 (5165), 1518-1519.

Michalek, I.M., Martinsen, J.I., Weiderpass, E., Kjaerheim, K., Lynge, E., Sparen, P., et al., 2019a. Occupation and risk of kidney cancer in Nordic countries. J. Occup. Environ. Med. 61 (1), 41-46.

Michalek, I.M., Martinsen, J.I., Weiderpass, E., Kjaerheim, K., Lynge, E., Sparen, P., et al., 2019b. Occupation and risk of cancer of the renal pelvis in Nordic countries. BJU Int. $123,233-238$.

Mickey, R.M., Greenland, S., 1989. The impact of confounder selection criteria on effect estimation. Am. J. Epidemiol. 129 (1), 125-137.

Moch, H., Cubilla, A.L., Humphrey, P.A., Reuter, V.E., Ulbright, T.M., 2016. The 2016 WHO Classification of tumours of the urinary system and male genital organs-Part A: renal, penile, and testicular tumours. Eur. Urol. 70 (1), 93-105.

Pesch, B., Haerting, J., Ranft, U., Klimpel, A., Oelschlägel, B., Schill, W., 2000 Dec. Occupational risk factors for renal cell carcinoma: agent-specific results from a casecontrol study in Germany. MURC Study Group. Multicenter urothelial and renal cancer study. Int. J. Epidemiol. 29 (6), 1014-1024.

Peters, C.E., Parent, M.E., Harris, S.A., Bogaert, L., Latifovic, L., Kachuri, L., et al., 2018a. Occupational exposure to diesel and gasoline engine exhausts and the risk of kidney cancer in Canadian men. Ann Work Expo Health.

Peters, C.E., Parent, M.E., Harris, S.A., Kachuri, L., Latifovic, L., Bogaert, L., et al., 2018b. Workplace exposure to asbestos and the risk of kidney cancer in Canadian men. Can. J. Public Health 109 (4), 464-472.

Pukkala, E., Engholm, G., Hojsgaard Schmidt, L.K., Storm, H., Khan, S., Lambe, M., et al., 2018. Nordic Cancer Registries - an overview of their procedures and data comparability. Acta Oncol. 57 (4), 440-455.

Pukkala, E., Martinsen, J.I., Lynge, E., Gunnarsdottir, H.K., Sparen, P., Tryggvadottir, L., et al., 2009. Occupation and cancer - follow-up of 15 million people in five Nordic countries. Acta Oncol. 48 (5), 646-790.

Rashidi, M., Alavipanah, S.K., 2016. Relation between kidney cancer and soil leads in Isfahan Province, Iran between 2007 and 2009. J. Cancer Res. Ther. 12 (2), 716-720.

Ron, I.G., Ron, H., Lerman, Y., 1999. Extrapulmonary neoplasms among asbestos-exposed power plant workers. Int. J. Occup. Environ. Health 5 (4), 304-306.

Sali, D., Boffetta, P., 2000. Kidney cancer and occupational exposure to asbestos: a metaanalysis of occupational cohort studies. Cancer Causes Control 11 (1), 37-47.

Sawada, N., Inoue, M., Sasazuki, S., Iwasaki, M., Yamaji, T., Shimazu, T., et al., 2010. Body mass index and subsequent risk of kidney cancer: a prospective cohort study in Japan. Ann. Epidemiol. 20 (6), 466-472.

Southard, E.B., Roff, A., Fortugno, T., Richie Jr., J.P., Kaag, M., Chinchilli, V.M., et al., 2012. Lead, calcium uptake, and related genetic variants in association with renal cell carcinoma risk in a cohort of male Finnish smokers. Cancer Epidemiol. Biomark. Prev. 21 (1), 191-201.

Statistics Finland, 2018. Quality of Work Life Surveys. [Available from: http://www.stat fi/tk/el/tyoolot_aineisto_en.html, Accessed date: 30 August 2018.

Wong, O., 1987. An industry wide mortality study of chemical workers occupationally exposed to benzene. I. General results. Br. J. Ind. Med. 44 (6), 365-381.

Xie, B., Hu, Y., Liang, Z., Liu, B., Zheng, X., Xie, L., 2016. Association between pesticide exposure and risk of kidney cancer: a meta-analysis. OncoTargets Ther. 9, 3893-3900. 